\title{
Serum selenium concentrations and dietary selenium intake of New Zealand children aged 5-14 years
}

\author{
Christine D. Thomson ${ }^{1}$, Sarah K. McLachlan ${ }^{1}$, Winsome R. Parnell ${ }^{1}$, Noela Wilson ${ }^{2}$, Mark Wohlers ${ }^{2}$, \\ Robert Scragg ${ }^{3}$, David Schaaf ${ }^{3}$ and Eljon D. Fitzgerald ${ }^{4}$ \\ ${ }^{1}$ Department of Human Nutrition and \\ ${ }^{2}$ LINZ Activity and Health Research Unit, University of Otago, Dunedin, New Zealand \\ ${ }^{3}$ School of Population Health, Faculty of Medicine and Health Science, University of Auckland, Auckland, New Zealand \\ ${ }^{4}$ School of Mäori Studies, Massey University, Palmerston North, New Zealand
}

(Received 22 March 2006 - Revised 6 September 2006 - Accepted 26 September 2006)

\begin{abstract}
Serum Se concentrations and dietary Se intakes have been determined in relation to age, sex, ethnicity, region and index of deprivation in a nationally representative sample of New Zealand children aged 5-14 years from the 2002 National Children's Nutrition Survey. Dietary intake was assessed from computer-assisted, multiple-pass $24 \mathrm{~h}$ diet recall interviews ( $n$ 3275). Serum Se concentrations were obtained from a subset of urban-based children $(n$ 1547). Mean $(95 \%$ CI) serum Se concentration in children was $0.96(0.93,1.00) \mu \mathrm{mol} / \mathrm{l}$. Males $(1.00 \mu \mathrm{mol} / \mathrm{l}) \mathrm{had}$ higher serum Se levels than females $(0.93 \mu \mathrm{mol} / 1 ; P=0.027)$. Mäori children had lower serum Se than Pacific Islands children $(P=0.038)$ and New Zealand European and Other children $(P=0.005)$. Children in the Upper North Island $(1.06 \mu m o l / l)$ had higher mean serum Se values than those in the Lower North Island $(0.98 \mu \mathrm{mol} / 1, P<0.0005)$ and South Island $(0.79 \mu \mathrm{mol} / 1, P<0.0005)$, and serum Se in the Lower North Island was higher than that in the South Island $(P<0.0005)$. Mean dietary Se intake was $36(34,37) \mu \mathrm{g} / \mathrm{d}$. The intakes of children aged $5-6$ years $(31 \mu \mathrm{g} / \mathrm{d})$ were lower than those of children aged $7-10$ and $11-14$ years (35 and $38 \mu \mathrm{g} / \mathrm{d}$, respectively; $P<0.00005)$ and the intakes of $7-10$-year-olds were lower than those of 11-14-year-olds $(P=0.002)$. Serum Se was associated with dietary Se after adjusting for all variables, including region $(P=0 \cdot 006)$. The Se status of our children falls in the middle of the international range of serum Se concentrations, but that for children in the South Island is among the lowest values reported and may be a cause for concern.
\end{abstract}

Serum Se: Se intakes: Children: New Zealand: Ethnicity

Se is a component of a number of important enzymes and selenoproteins, and has been shown to be involved in protection against viral infection and cancer, in immune function and in the aetiology of I-deficiency disorders (Rayman, 2000; Combs, 2001). In infants and children, a low Se status has been implicated in the aetiology of Keshan disease (Chen et al. 1980), cretinism associated with I deficiency (Zimmerman \& Kohrle, 2002; Chanoine, 2003), asthma (Stone et al. 1989; Flatt et al. 1990; Shaw et al. 1994; Rubin et al. 2004) and chronic lung disease in preterm infants (Darlow et al. 1995). The association between low Se status and asthma is of particular interest in New Zealand, where there is a high incidence of asthma in children (Shaw et al. 1994).

Research in Dunedin and Christchurch in the South Island of New Zealand has consistently shown a low Se status in adults, infants and children in comparison to many other countries (McKenzie et al. 1978; Thomson \& Robinson, 1996; Combs, 2001; McLachlan et al. 2004; Thomson, $2004 a$ ). The increase in activity of glutathione peroxidase (GPx) and selenoprotein $\mathrm{P}$ that has been observed in response to Se supplementation in South Island residents indicates that their Se status is inadequate for optimal levels of some important selenoproteins (Thomson et al. 1993; Duffield et al. 1999).

There has been only one previous study of the Se status of New Zealand children (McKenzie et al. 1978), which was carried out in Dunedin in the 1970s, before the observed increase in Se status in adults over the past decade (Thomson \& Robinson, 1996). Se was determined in whole blood of a small number of healthy children aged 5-13 years in Auckland (North Island), Dunedin and Tapanui (South Island), and mean Se concentrations were clearly lower than adult values in Auckland and Tapanui but not in Dunedin. Se status varied geographically from North to South, the highest blood Se concentrations being observed in Auckland and the lowest in Tapanui, a South Island area with a particularly low soil content of Se.

Because of the large geographical variation in soil Se and the variation in the bioavailability of Se from different soils, and consequently in Se intakes and status, there are no established international reference ranges for plasma or serum Se

Abbreviations: CNS02, 2002 National Children's Nutrition Survey; GPx, glutathione peroxidase; NZDep2001, New Zealand Index of Deprivation 2001; NZEO, New Zealand European and Other.

* Corresponding author: Professor Christine D. Thomson, fax 6434797958, email christine.thomson@ stonebow.otago.ac.nz 
for adults or children (Thomson, 2004b). Furthermore, in adults, it appears that different concentrations of plasma Se are required to satisfy optimal levels of different selenoproteins (Thomson, 2004b; Xia et al. 2005), illustrating a hierarchy of importance of these selenoproteins (Behne et al. 1989). Although this makes the diagnosis of Se deficiency or inadequacy difficult, the establishment of country-specific reference ranges is of some practical value in identifying those at particular risk of deficiency.

In the current paper, we present the serum Se concentrations and dietary Se intakes from the 2002 National Children's Nutrition Survey (CNS02), a large nationally representative sample of New Zealand school-age children and adolescents. The survey provides a unique opportunity to explore the effects of ethnicity in the three ethnic groups - Mäori, Pacific (Samoan, Tongan, Cook Island Mäori, Niuean, Tokelauan, Fijian) and New Zealand European and Other (NZEO) children - as well as regional variation and the relationship between serum Se and dietary intake.

\section{Methods}

\section{Study design and population}

The CNSO2 was a cross-sectional survey of a national sample of New Zealand school children and adolescents aged 5-14 years. A school-based sampling frame of children was used with an oversampling of Mäori and Pacific children to allow ethnic-specific analysis (Parnell et al. 2003). The sample was recruited using a two-stage process involving a random selection of schools followed by a random selection of children within each school. The final sample was selected from 172 schools (91\% of the schools selected). Once a school had been selected, the register of students aged 5-14 years was divided into the three ethnic groups (Mäori, Pacific, NZEO). To ensure that the final sample included approximately 1000 children in each of the three ethnic groups, children within each ethnic group were selected according to the following sampling proportions based on the latest available Ministry of Education school rolls: Pacific 0.410, Mäori $0 \cdot 161$ and NZEO $0 \cdot 050$, respectively, of the available children in each group. Sampling proportions included an inflation factor to allow for a $70 \%$ response rate. From the 172 schools, 4728 children were selected; of these, 3275 participated (response rate $69.3 \%$ ).

Because of the difficulty in obtaining blood samples from participants in rural areas and budget constraints, blood samples were obtained from 1927 children in urban schools. Serum was available for Se analysis only for 1621 of the 1927 participants, as Se was relatively low on the priority list of nutrients to be analysed in this survey. Of these, all data relevant to this study were available for 1547 children, yielding an overall response rate of $32.7 \%$ (1547 of the 4728 children selected). There was an insufficient adequately stored sample for the analysis of GPx activities. The survey received ethical approval from the Auckland Ethics Committee and thirteen regional health ethics committees. Informed written consent was obtained from both the children and their parents or guardians.

Demographic data were obtained during interviews at the children's homes or at school in the presence of their parents or guardians. Interviews were conducted from the last week of February 2002 to the second week of December 2002. Ethnicity was self-reported by each child, or their parents or guardians, with the option to choose up to three ethnic groups. A single ethnic category was assigned to each child using the New Zealand census system of priority recoding of ethnicity: Mäori, Pacific and all remaining NZEO. Pacific children included those who identified as Samoan, Tongan, Cook Island Mäori, Niuean, Tokelauan, Fijian and other Pacific ethnic groups. The NZEO group included New Zealand European, Asian, Other European, Indian and other.

Children were also classified according to the $2001 \mathrm{New}$ Zealand Index of Deprivation (NZDep2001), which is an index based on an individual's residential address (Salmond $\&$ Crampton, 2002). The deprivation score for each meshblock (geographical locations defined by Statistics New Zealand containing a median of 90 people in 2001) is based on eight dimensions of deprivation: income, access to a car, living space, home ownership, employment, qualifications, support and access to a telephone. The usual ten categories on the scale were collapsed into quintiles, quintile I being defined as children living in the least deprived areas and quintile $\mathrm{V}$ as children living in the most deprived areas.

A non-fasting blood sample was drawn from an antecubital vein into evacuated tubes. Samples were centrifuged, the serum was removed and aliquoted into cryovials within $24 \mathrm{~h}$ of collection, and surplus serum was stored at $-80^{\circ} \mathrm{C}$ for subsequent analysis. The samples were thawed and refrozen once only prior to analysis of Se, and were stored for 18-24 months before analysis.

Dietary intake of Se was assessed from a computerassisted, multiple-pass $24 \mathrm{~h}$ diet recall interview structured into three phases to maximise the child's recall of foods eaten (Parnell et al. 2003). The first pass, the 'quick list', involved supplying a broad description of foods, beverages and dietary supplements consumed in the previous $24 \mathrm{~h}$. In the next stage, a detailed description of each food, beverage or dietary supplement on the quick list was ascertained through a series of programme-controlled questions and prompts specific to each item, including time of consumption, amount consumed and cooking method. The third pass was a review of the recall to verify the descriptions and amounts of foods consumed. All children under 10 years of age were interviewed, with input from a parent or adult caregiver.

This process used a direct computer data entry system, a Windows-based program that utilised the World Wide Web to deliver completed interviews back to the project office. The questioning reflected foods likely to be consumed by children. The multiple-pass recall interview was structured into three steps to maximise the child's recall of foods eaten. The programme contained a comprehensive food list that comprised all the known foods and beverages available for consumption in New Zealand. Nutrient analysis was carried out using the New Zealand Food Composition Database, which contains the composition of approximately 2000 foods, values representing the average composition of foods sampled in all regions of the country (Manufactured Food Database, 2002; New Zealand Institute of Crop \& Food Research Ltd, 2002). Therefore, the Se intakes reported represent average intakes across the whole country. 
The day-to-day variation in nutrient intake was estimated by repeating the $24 \mathrm{~h}$ diet recall on a subsample of children ( $n$ 505). This was then used to adjust the reported nutrient intakes and estimate the distribution of 'usual' intakes of dietary components in the population using the software package PC-SIDE (developed by Iowa State University).

In order to calculate the dietary sources of Se, food items reported in the $24 \mathrm{~h}$ diet recall were allocated to food groups. The food groups used in the CNS02 (Parnell et al. 2003) were collapsed into the following groups: Bread (all types of bread); Bread/Grain (a composite including bread, grains and pasta, biscuits, cakes and muffins, bread-based dishes and breakfast cereals); Dairy (a composite including dairy products, milk, cheese, butter and also margarine); Fish/Seafood (all fish, shellfish, squid, crab and fish/seafood dishes and products); Fruit/Vegetables (a composite of vegetables, potatoes, kumara and taro, and fruit); Meat (a composite of beef and veal, lamb and mutton, pork, other meat, sausages and processed meats); Poultry (chicken, duck, turkey and muttonbird muscle meats). The average percentages of Se from the various food groups were calculated as the percentage of Se from each food group for each individual, and then averaged over the sample. Sampling weights were used to give an estimate of the population average (see Statistical Analysis).

\section{Selenium analysis}

Se levels were analysed using graphite furnace atomic absorption spectrometry. Multiple aliquots of a control pooled plasma sample were analysed during each batch of analysis to check the analytical precision. The mean value for the pooled control was 1.03 (SD 0.06) $\mu$ mol/l ( $n$ 59, CV 5.8\%). In addition, an external control, Utak Reference Plasma (batch 66816, lot 6312), was analysed with each batch. The analysed values lay within the expected range given by the manufacturer (i.e. 1.20-2.00 $\mu \mathrm{mol} / \mathrm{l}$; certified mean concentration $1.59 \mu \mathrm{mol} / \mathrm{l})$, with a mean of 1.25 (SD 0.07 ) $\mu \mathrm{mol} / \mathrm{l}$ ( $\mathrm{5}$, CV $5.4 \%)$.

\section{Data analysis}

Statistical analyses were conducted using STATA 8.0 (StataCorp, College Station, TX, USA), adjusting for the complex survey design. Sampling weights, which were the inverse of the probability of being selected, were used in all analyses to obtain unbiased estimates of population serum Se concentrations and intakes. Sampling weights for serum Se concentrations were based on the number of children selected for provision of a blood sample rather than for participation in the survey, as only children from urban areas were sampled for blood. Sampling weights included adjustment for differential non-response and post-stratification by age, sex and ethnicity. The effect of age, sex, ethnicity, index of deprivation (NZDep2001) and regional location on serum Se concentrations and Se intakes was determined by multiple regression. The multiple regression model allowed the effect of each explanatory variable on the serum Se concentrations to be assessed individually while controlling for the joint influence of the other explanatory variables in the model. The relationship between daily Se intake and serum Se concentrations was also investigated using a multiple regression model, controlling for age, sex, ethnicity, index of deprivation and region. The number of children for whom all data were available for statistical analysis was 1547 .

\section{Results}

Characteristics of the sample of children for whom serum Se and dietary Se were available ( $n$ 1547) were compared with those of the total CNS02 sample ( $n$ 3275), for whom only dietary data were available (Table 1). The distribution of sex and age did not differ between these groups. Although there were differences in the ethnic mix of the two samples because of geographical variations in ethnic distribution, this was accounted for in the statistical analysis by the use of separate sampling weights for the serum Se sample and the total CNS02 sample. Dietary Se intakes for the participants providing serum Se were not significantly different from the dietary intakes of the complete sample of New Zealand children (Table 1). Furthermore, dietary Se intakes of the two samples did not differ when divided according to sex, age, ethnicity and region (data not shown).

\section{Serum selenium concentrations}

The unadjusted mean $(95 \% \mathrm{CI})$ serum Se concentration in these New Zealand children in 2002 was 0.96 (0.93, 1.00) $\mu \mathrm{mol} / \mathrm{l}$ (Table 2). A reference range for children aged 5-14 years $(2.5-97.5$ percentile) established from these data was $0.673-1.319 \mu \mathrm{mol} / 1 \quad(53 \cdot 2-104.2 \mu \mathrm{g} / \mathrm{l})$. Boys had higher serum Se levels than girls $(P=0 \cdot 027)$. Children aged 5-6 years had a lower mean serum Se concentration than that of the two other age groups, but the differences were not significant. Mäori children had significantly lower mean serum Se than Pacific Islands children and NZEO children $(P=0.038$ and $P=0.005$, respectively). There was no effect of index of deprivation on serum Se after controlling for all other variables (Table 3).

Table 1. Characteristics of all participants in the 2002 Children's Nutrition Survey, and participants with a serum Se result

\begin{tabular}{lcc}
\hline & $\begin{array}{c}\text { All survey } \\
\text { participants } n(\%)\end{array}$ & $\begin{array}{c}\text { Participants with a } \\
\text { serum Se result } n(\%)\end{array}$ \\
\hline $\begin{array}{l}\text { All children } \\
\text { Sex }\end{array}$ & 3275 & 1547 \\
$\quad$ Boys & $1697(52)$ & $790(51)$ \\
$\quad$ Girls & $1578(48)$ & $757(49)$ \\
Age (years) & & \\
$5-6$ & $692(21)$ & $297(19)$ \\
$7-10$ & $1425(44)$ & $711(46)$ \\
$11-14$ & $1158(35)$ & $539(35)$ \\
Ethnicity & & \\
$\quad$ Mäori & $1224(37)$ & $444(29)$ \\
Pacific & $1058(32)$ & $652(42)$ \\
$\quad$ NZEO & $993(30)$ & $451(29)$ \\
Region & & \\
Upper North Island & $1614(49)$ & $921(60)$ \\
Lower North Island & $1123(34)$ & $472(31)$ \\
$\quad$ South Island & $538(16)$ & $154(10)$ \\
Dietary Se intake & $37(33,39)$ & $36(35,37)$ \\
$\quad(\mu g / d ;$ mean $(95 \% \mathrm{Cl}))$ & & \\
\hline
\end{tabular}

In the Children's Nutrition Survey, a participant was defined as a child or adolescent who completed a $24 \mathrm{~h}$ diet recall.

NZEO, New Zealand European and Others. 
Table 2. Mean serum Se concentrations and dietary Se intakes of New Zealand children by age, gender and ethnicity

(Mean values and $95 \% \mathrm{Cl}$ )

\begin{tabular}{|c|c|c|c|c|c|}
\hline & \multirow[b]{2}{*}{$n$} & \multicolumn{2}{|c|}{ Serum Se $(\mu \mathrm{mol} / \mathrm{l})$} & \multicolumn{2}{|c|}{$\begin{array}{c}\text { Dietary Se } \\
\text { intake }^{*}(\mu \mathrm{g} / \mathrm{d})\end{array}$} \\
\hline & & Mean & $95 \% \mathrm{Cl}$ & Mean & $95 \% \mathrm{Cl}$ \\
\hline All children & 1547 & 0.96 & $0.93,1.00$ & 36 & 34,37 \\
\hline \multicolumn{6}{|l|}{ Age (years) } \\
\hline $5-6$ & 297 & 0.94 & $0.90,0.98$ & $31 \S$ & 29,33 \\
\hline $7-10$ & 711 & 0.97 & $0.93,1.01$ & $35 \S$ & 34,37 \\
\hline $11-14$ & 539 & 0.96 & $0.91,1.02$ & $38 \S$ & 36,40 \\
\hline \multicolumn{6}{|l|}{ Sex } \\
\hline Male & 790 & $1.00 t$ & $0.96,1.04$ & 38 & 36,39 \\
\hline $5-6$ years & 164 & 0.99 & $0.94,1.03$ & 32 & 30,35 \\
\hline $7-10$ years & 359 & 1.00 & $0.96,1.04$ & 36 & 34,39 \\
\hline $11-14$ years & 267 & 0.99 & $0.91,1.07$ & 41 & 39,44 \\
\hline Female & 757 & $0.93 \dagger$ & $0.89,0.97$ & 34 & 32,35 \\
\hline $5-6$ years & 133 & 0.91 & $0.85,0.96$ & 30 & 27,33 \\
\hline $7-10$ years & 352 & 0.94 & $0.89,0.99$ & 34 & 32,36 \\
\hline $11-14$ years & 272 & 0.93 & $0.88,0.99$ & 35 & 32,38 \\
\hline \multicolumn{6}{|l|}{ Ethnicity } \\
\hline Mäori & 444 & $0.96 \ddagger$ & $0.94,0.99$ & 37 & 35,39 \\
\hline Male & 231 & 0.98 & $0.95,1.01$ & 40 & 36,43 \\
\hline Female & 213 & 0.94 & $0.91,0.98$ & 35 & 32,37 \\
\hline Pacific & 652 & $1.03 \ddagger$ & $1.01,1.05$ & 39 & 37,40 \\
\hline Male & 306 & 1.05 & $1.02,1.08$ & 41 & 39,42 \\
\hline Female & 346 & 1.02 & $1.00,1.04$ & 36 & 35,38 \\
\hline NZEO & 451 & $0.95 \ddagger$ & $0.91,1.00$ & 35 & 34,36 \\
\hline Male & 253 & 0.99 & $0.94,1.05$ & 37 & 35,39 \\
\hline Female & 198 & 0.92 & $0.87,0.96$ & 33 & 31,35 \\
\hline
\end{tabular}

All data were adjusted for survey weighting.

NZEO, New Zealand European and Others.

* Usual intake; these data were adjusted for intra-individual variation using PC SIDE multiple regression controlling for age, sex, ethnicity, index of deprivation (New Zealand Index of Deprivation 2001) and region.

$\dagger$ Serum Se greater in males than females $(P=0.027)$.

$\ddagger$ Serum Se lower in Mäori than Pacific $(P<0.038)$ and NZEO children $(P=0.005)$.

$\S$ Se intake lower in 5-6-year-old children than $7-10$-year-old $(P<0.00005)$ and $11-14$-year-old children $(P<0.00005)$, and lower in $7-10$-year-old than $11-14$ year-old children $(P=0.0002)$.

Clear regional differences were observed after adjusting for all other factors (Table 3). Children in the Upper North Island Region (Auckland/Northland) had mean serum Se concentrations higher than those in the Lower North Island (all other North Island regions $P<0.0005)$ and the South Island (Marlborough, Canterbury, Otago, Southland; $P<0.0005$ ). The mean serum $\mathrm{Se}$ in the Lower North Island was also greater than that in the South Island $(P<0 \cdot 0005)$.

An interaction between ethnicity and region was investigated, controlling for NZDep2001, age and sex. Although there was evidence of an ethnicity effect $(P<0.00005)$ and a region effect $(P<0.00005)$, there was not sufficient evidence for an interaction between ethnicity and region $(P=0 \cdot 077$; Table 3$)$.

\section{Dietary selenium intakes}

Dietary Se intakes were available for the full CNS02 sample ( $n$ 3275) and for those for whom serum Se and other data were available ( $n$ 1547). A comparison of intakes for these two sample groups showed no significant differences for all children (Table 1 above), boys and girls, the three ethnic groups or the three age groups. Dietary Se intakes for the serum Se group only are presented in Table 2 earlier. There were no significant differences in Se intake between males
Table 3. Serum Se concentrations and dietary Se intakes of New Zealand children by region and index of deprivation*

(Mean values and $95 \% \mathrm{Cl}$ )

\begin{tabular}{|c|c|c|c|c|c|}
\hline & \multirow[b]{2}{*}{$n$} & \multicolumn{2}{|c|}{ Serum Se $(\mu \mathrm{mol} / \mathrm{l})$} & \multicolumn{2}{|c|}{$\begin{array}{c}\text { Dietary Se } \\
\text { intake* }^{*}(\mu \mathrm{g} / \mathrm{d})\end{array}$} \\
\hline & & Mean & $95 \% \mathrm{Cl}$ & Mean & $95 \% \mathrm{Cl}$ \\
\hline \multicolumn{6}{|l|}{ Region } \\
\hline Upper North Island & 921 & $1.06 \dagger$ & $1.02,1 \cdot 11$ & 37 & 35,40 \\
\hline Mäori & 220 & 1.01 & $0.98,1.03$ & & \\
\hline Pacific & 550 & 1.05 & $1.03,1.06$ & & \\
\hline NZEO & 151 & $1 \cdot 10$ & $1 \cdot 04,1 \cdot 15$ & & \\
\hline Lower North Island & 472 & 0.98 & $0.95,1.00$ & 35 & 34,37 \\
\hline Mäori & 192 & 0.95 & $0.92,0.99$ & & \\
\hline Pacific & 85 & 1.03 & $0.99,1.06$ & & \\
\hline NZEO & 195 & 0.98 & $0.96,1.01$ & & \\
\hline South Island & 154 & 0.79 & $0.76,0.82$ & 34 & 32,36 \\
\hline Mäori & 32 & 0.78 & $0.74,0.83$ & & \\
\hline Pacific & 17 & 0.80 & $0.74,0.86$ & & \\
\hline NZEO & 105 & 0.79 & $0.75,0.82$ & & \\
\hline \multicolumn{6}{|l|}{ NZDep2001 quintile } \\
\hline I & 136 & 0.94 & $0.88,1.00$ & $35 \ddagger$ & 32,37 \\
\hline II & 177 & 0.95 & $0.90,1.01$ & 34 & 31,37 \\
\hline III & 194 & 0.97 & $0.91,1.03$ & 35 & 33,38 \\
\hline IV & 288 & 0.98 & $0.94,1.02$ & 37 & 34,39 \\
\hline V & 752 & 0.97 & $0.94,1.00$ & 37 & 35,40 \\
\hline
\end{tabular}

All data were adjusted for survey weighting.

NZEO, New Zealand European and Others; NZDep2001, New Zealand Index of Deprivation 2001.

* Usual intake; these data were adjusted for intra-individual variation using PCSIDE multiple regression controlling for age, sex, ethnicity, index of deprivation (NZDep2001) and region.

†Serum Se was greater in the Upper North Island than the Lower North Island $(P<0.0005)$, the Upper North Island than the South Island $(P<0.0005)$ and the Lower North Island than the South Island $(P<0.0005)$.

$\ddagger$ Se intakes were greater in NZDep2001 IV than NZDep2001 II $(P=0.002)$ and III $(P=0.021)$ in males; there was a trend for higher Se intakes with a lower index of deprivation $(P=0.044)$.

and females or between ethnic groups. Se intakes of the children aged 5-6 years were lower than those of 7-10- and 11-14-year-old children $(P<0.00005)$, and the intakes of children aged 7-10 years were lower than those of children aged 11-14 years $(P=0 \cdot 002)$. There was no significant effect of geographical region on Se intake (Table 3 ). There was a trend $(P=0.044)$ for higher Se intakes in the lowest NZDep2001 groups (quintiles IV and V).

The major contributors of Se to total dietary intake for the full CNS02 sample were Bread/Grain (mean contribution $33 \%)$, Meat $(14.8 \%)$, Poultry $(11.2 \%)$ and Fish/Seafood (8.6\%; Table 4). However, when data for fish consumers only (498 of the total 3275 children) were analysed, fish and seafood contributed a much larger proportion of total Se intake $(65 \%)$. The large influence of fish consumption on total dietary intake is in part reflected in the higher serum Se concentrations and Se intake in Pacific children. The contribution of fish to the total dietary intake of Mäori, Pacific and NZEO children was $10.0,13.8$ and $6.7 \mu \mathrm{g} \mathrm{Se} / \mathrm{d}$, with a mean percentage contribution of $9.3,13.1$ and $7.8 \%$, respectively.

\section{Relationship between serum selenium and dietary selenium intake}

Multiple regression showed a significant effect of dietary Se on serum Se concentration in this group of children when 
controlling for age, sex, ethnicity, index of deprivation and regional location $(P=0 \cdot 006)$. There was, however, no significant effect when region was removed from the regression model $(P=0 \cdot 075)$.

\section{Discussion}

This is the first time that Se status has been determined in a nationally representative sample of New Zealand children. From these results, we can establish a reference range for this group of New Zealand children aged 5-14 years of $0.67-1.32 \mu \mathrm{mol} / 1$ based on the central $95 \%$ interval bounded by the 2.5 and 97.5 percentiles. Although these data were collected only on urban-based children, the separate weighting of the data for the children for whom both serum Se and dietary Se were available and for the total CNS02 sample provides the best available estimate of a reference range for New Zealand children. Furthermore, there were no significant differences in dietary Se intake between the total CNSO2 sample and the serum Se group (Table 2 above). It is also important to recognise that, because there is insufficient information on which to determine a cut-off for adequate Se status, this interval does not necessarily represent a healthy normal range.

Although there is no international reference range, results from our New Zealand children can be compared with those reported from other countries. Several groups have determined the Se status of healthy children in comparison with children with various conditions, such as asthma and hypothyroidism (Table 5). Of these, only the group of children in the 3rd US National Health and Nutrition Examination Survey (Rubin et al. 2004) and the UK National Diet and Nutrition Survey (Gregory \& Lowe, 2000) can be considered as truly nationally representative samples. Clearly, as a whole, our children fall in the middle of the range of international serum Se concentrations. The Se status of children in the South Island of New Zealand is, however, among the lowest values reported internationally (Table 5). This geographical variation mirrors what has been observed in adults, with a higher Se status for adults in Auckland, Wellington and Hamilton in the North Island than in the Otago and Canterbury regions in the South Island (Thomson \& Robinson, 1996; Thomson, 2004a). Comparison with the one previous study of blood Se concentration of New Zealand children

Table 4. Contribution of food group sources of Se to total dietary Se intake of New Zealand children

\begin{tabular}{|c|c|c|c|c|}
\hline \multirow[b]{2}{*}{ All children ( $n$ 3275) } & \multicolumn{2}{|c|}{ Se intake $(\mu \mathrm{g} \mathrm{Se} / \mathrm{d})$} & \multicolumn{2}{|c|}{$\%$ total intake* } \\
\hline & Mean & $95 \% \mathrm{Cl}$ & Mean & $95 \% \mathrm{Cl}$ \\
\hline \multicolumn{5}{|l|}{ Food group } \\
\hline Fish/Seafood & $8 \cdot 1$ & $6.7,9.5$ & $8 \cdot 6$ & $7 \cdot 4,9 \cdot 8$ \\
\hline Poultry & 4.4 & $4 \cdot 0,5 \cdot 0$ & $11 \cdot 2$ & $10 \cdot 2,12 \cdot 2$ \\
\hline Meat & 4.6 & $4 \cdot 2,5 \cdot 0$ & $14 \cdot 8$ & $13 \cdot 9,15 \cdot 7$ \\
\hline Bread & 3.9 & $3 \cdot 6,4 \cdot 1$ & 13.4 & $12 \cdot 7,14 \cdot 1$ \\
\hline Bread/Grain & $10 \cdot 4$ & $9.8,11.0$ & 33.1 & $31 \cdot 8,34 \cdot 6$ \\
\hline Dairy & 2.5 & $2 \cdot 3,2 \cdot 7$ & $9 \cdot 1$ & $8 \cdot 4,9 \cdot 8$ \\
\hline Fruit/Vegetables & $2 \cdot 2$ & $2 \cdot 0,2 \cdot 4$ & 7.9 & $7.4,8.5$ \\
\hline \multicolumn{5}{|c|}{ Fish consumers ( $n$ 498) } \\
\hline Fish and seafood & 61 & 54,68 & 65 & 61,68 \\
\hline
\end{tabular}

${ }^{*}$ Mean of individual percentage contributions.
(McKenzie et al. 1978) indicates that, as for adults, Se status has increased over the past decades due to factors including wheat importation, increases in the Se content of some animal foods and changes in dietary patterns (Thomson \& Robinson, 1996), but it is still low in comparison with that of many other countries.

It is important to note that the regional results are limited because the survey was not designed to provide information at this level. However, the observation of a marked geographical variation in plasma Se from the north of the North Island to the South Island of the country confirms other observations of regional differences in Se status in New Zealand (Watkinson, 1981; Thomson \& Robinson, 1996). This variation is clearly related to the extent to which imported Australian wheat, with a higher Se concentration, is used for making bread and other bakery products. In the north of the North Island, there is a greater (up to $100 \%$ ) use of Australian wheat than there is in the south of the North Island $(30-35 \%)$, whereas in the South Island all wheat used is normally grown locally (personal communication, N. Athar, New Zealand Institute of Crop and Food Research).

The 2003/04 New Zealand Total Diet Survey found Se concentrations in white bread, wheatmeal bread and mixed grain bread of around $22-131 \mu \mathrm{g} / \mathrm{kg}$ in Auckland, 38-102 $\mu \mathrm{g} / \mathrm{kg}$ in Napier (Lower North Island) and less than $10-16 \mu \mathrm{g} / \mathrm{kg}$ in Dunedin and Christchurch in the South Island (Vannoort \& Thomson, 2005). Based on the mean bread intake of the children and the mean Se concentrations of twelve bread samples collected in the North Island $(71 \mu \mathrm{g} / \mathrm{kg})$ and twelve collected in the South Island $(11 \mu \mathrm{g} / \mathrm{kg})$, an approximate estimate of the difference in Se intake from bread between the North and South Islands is $5 \mu \mathrm{g} / \mathrm{d}$.

Bread is the only food known to differ to any great extent in Se concentration around the country (Vannoort \& Thomson, 2005). Others foods do not differ significantly because all New Zealand soils are relatively low in Se, and even though there is some variation around the country, vegetables and fruits grown on these soils are poor sources of Se. Poultry and animals in low-Se areas are routinely supplemented with Se through the top-dressing of pastures as well as inorganic supplements, and the use of high-Se meal for poultry feeds; this is reflected in similar Se concentrations in animal foods from different regions (Vannoort \& Thomson, 2005). Furthermore, there is a considerable distribution of food throughout the country. Another dietary influence that might have contributed to the geographical variation in serum Se was the high fish and poultry intake of Pacific children, of whom there was a higher proportion in the north of the North Island $(60 \%)$ than in the Lower North Island $(18 \%)$ and the South Island $(11 \%)$.

Mean serum Se concentration was lowest in 5-6-year-old children, although there were no significant differences across the age groups, in spite of significantly lower dietary intakes for the youngest group. There is a wide range of age groups in reported studies, but most are around the 5-14year age range of our children. A small number of studies have reported variations with age (Lombeck, 1977; Jacobson \& Lockitch, 1988; van Biervliet et al. 2001; Cser et al. 2002; Muntau et al. 2002), and it appears from most of these studies that $\mathrm{Se}$ concentrations reach adult levels at an age of about 5-10 years. Results from the present study 
Table 5. Serum/plasma Se concentrations in children from selected countries (Mean values are and standard deviations)

\begin{tabular}{|c|c|c|c|c|c|c|}
\hline & \multirow[b]{2}{*}{ Age (years) } & \multirow[b]{2}{*}{$n$} & \multicolumn{3}{|c|}{ Serum/plasma Se $(\mu \mathrm{mol} / \mathrm{l})$} & \multirow[b]{2}{*}{ Author(s) } \\
\hline & & & Mean & SD & Range & \\
\hline Austria & $1-15$ & 109 & $0.61^{*}$ & & $0.43-0.76$ & Rossipal \& Tiran (1995) \\
\hline \multirow[t]{2}{*}{ Belgium } & $2-15$ & 16 & 0.97 & $0 \cdot 16$ & $0.67-1.32$ & $\begin{array}{l}\text { van Caillie-Bertrand et al. } \\
\quad(1986)\end{array}$ \\
\hline & $4-14$ & 192 & 0.75 & & $0.67-0.86$ & van Biervliet et al. (2001) \\
\hline Canada & $1-9$ & 40 & 1.60 & & $1.52-1.67$ & Jacobson \& Lockitch (1988) \\
\hline Croatia & $8-15$ & 63 & 0.72 & 0.11 & & Becker et al. (1992) \\
\hline England & $4-16$ & 49 & $0.99^{\star}$ & & & Thomas et al. (1994) \\
\hline \multirow[t]{2}{*}{ Finland } & $1-19$ & $\begin{array}{r}144 \\
95\end{array}$ & $\begin{array}{l}0.87(1985) \\
1.34(1987)\end{array}$ & & & Wang et al. (1995) \\
\hline & $9-15$ & 322 & 1.32 & $0 \cdot 14$ & & $\begin{array}{l}\text { Mussalo-Rauhamaa et al. } \\
\text { (1993) }\end{array}$ \\
\hline \multirow[t]{2}{*}{ Germany } & $5-18$ & 623 & $0.98^{\star}$ & & $0.94-1.00 \dagger$ & Muntau et al. (2002) \\
\hline & $5-15$ & 34 & 0.87 & 0.19 & & Jochum et al. (1999) \\
\hline \multirow[t]{2}{*}{ Greece } & $6-10$ & 18 & 0.72 & $0 \cdot 11$ & & van Cauwenbergh et al. (1995) \\
\hline & $11-20$ & 17 & 0.76 & 0.20 & & \\
\hline Hungary & $6-15$ & 119 & 0.66 & 0.09 & & Cser et al. (1996) \\
\hline Italy & $12-13$ & 627 & 1.04 & $0 \cdot 13$ & & Marano et al. (1991) \\
\hline \multirow[t]{3}{*}{ Poland } & $7-15$ & 78 & $0.97(1980-82)$ & $0 \cdot 18$ & & Wasowicz et al. (2003) \\
\hline & & 44 & $0.47(1990-91)$ & $0 \cdot 12$ & & \\
\hline & $5-18$ & 27 & 1.08 & 0.06 & & Zwolinska et al. (2004) \\
\hline \multirow[t]{2}{*}{ Slovakia } & $11-18$ & 891 & 0.76 & & $0.75-0.77$ & Brtková et al. (1994) \\
\hline & $1-13$ & 71 & 1.08 & & $0.95-1.19 \dagger$ & Micetic-Turk et al. (1996) \\
\hline Spain & $7-14$ & 86 & 0.72 & 0.2 & $0.34-1.10$ & Fraga et al. (1994) \\
\hline Sweden & 15 & 372 & 1.39 & 0.25 & & Barany et al. (2002) \\
\hline \multirow[t]{2}{*}{ Turkey } & $2-16$ & 76 & 0.94 & $0 \cdot 18$ & & Hincal et al. (1994) \\
\hline & $9-11$ & 251 & 0.68 & $0 \cdot 18$ & & Erdogan et al. (2001) \\
\hline \multirow[t]{2}{*}{ UK } & $4-18$ & $591 \mathrm{M}$ & $0.86(1997)$ & 0.15 & & Gregory \& Lowe (2000) \\
\hline & & $540 \mathrm{~F}$ & 0.87 & $0 \cdot 16$ & & \\
\hline \multirow[t]{2}{*}{ USA } & $1-18$ & 83 & 1.35 & & & Glauser et al. (1999) \\
\hline & $4-16$ & 5305 & 1.48 & $0 \cdot 18$ & & Rubin et al. (2004) \\
\hline \multirow[t]{2}{*}{ Venezuela } & $2-14$ & & $2 \cdot 15$ (Region 1) & 0.46 & & Bratter et al. (1991) \\
\hline & & & 4.30 (Region 2) & 0.22 & & \\
\hline Yugoslavia & $1-16$ & 79 & 0.68 & 0.07 & & Mikac-Devic et al. (1990) \\
\hline
\end{tabular}

* Overall median and range of median.

†Range of mean.

indicate that although the 5-6-year-old children appear to have lower serum Se values, there is little difference from 7 through to 14 years. Serum Se concentrations for Otago/ Southland children $(0.82$ (SD 0.03$) \mu \mathrm{mol} / \mathrm{l})$ in the present study are, however, still somewhat lower than recently reported plasma Se concentrations in Otago adults (1.11 (SD 0.18) $\mu \mathrm{mol} / \mathrm{l}$; Thomson, 2004a).

The reason for the higher Se status of Pacific children than of Mäori and NZEO children is likely to be due to a combination of dietary differences, including higher fish intake and the importation of Australian wheat into the upper North Island, where the majority of Pacific children reside. The difference between Mäori and NZEO children may be even greater than indicated from these results because of the higher Se status associated with the importation of Australian wheat to the North Island, where most of the Mäori population resides.

Plasma Se status has been shown to be related to dietary Se intake on an individual (Duffield \& Thomson, 1999) and a population (Levander, 1982) basis. In this group of children, the relationship was significant $(P=0 \cdot 006)$ when controlling for all factors including geographical region, but not when region was excluded from the multiple regression model. This is reflected in regional differences in serum $\mathrm{Se}$ concentration but not dietary Se intake (Table 3 earlier). One reason for this discrepancy is that the New Zealand Food Composition Database (New Zealand Institute of Crop \& Food Research Ltd, 2002) includes mean concentrations for cereal foods, particularly bread, collected throughout the country, and does not take into account the regional differences in food Se concentration. For example, as previously indicated, Se concentrations in white bread may vary from less than $10 \mu \mathrm{g} / \mathrm{kg}$ in Dunedin and Christchurch up to $101 \mu \mathrm{g} / \mathrm{kg}$ in Auckland (Vannoort \& Thomson, 2005), whereas the concentrations used in calculating the dietary data for children in all regions would be the mean of all values, $35 \mu \mathrm{g} / \mathrm{kg}$. Other possible reasons for the discrepancy include the limitations of one $24 \mathrm{~h}$ diet record for assessing an individual's usual intake of $\mathrm{Se}$, even though the nutrient data were adjusted for intra-individual variation using PC-SIDE (developed by Iowa State University), and the likely day-to-day individual variation in dietary intake, particularly among foods not eaten daily, such as fish. These geographical distribution differences in the three ethnic groups illustrate some of the difficulties associated with dietary analysis for assessment of Se status.

The lack of an established reference range for serum Se in either adults or children arises from the strong geographical 
influence on Se status and from the lack of information on the association between Se concentrations and disease states, particularly in children. Thomson (2004b) has estimated unofficial cut-off values for functional roles for $S e$ such as optimal GPx activity, optimal deiodinase activity and protection against cancer in adults. It is not known whether these are applicable to children, and it is unfortunate that we were not able to determine GPx activity in these children. However, given that serum Se values appear to reach adult values at an early age, we can draw some conclusions from our results.

As the plasma/serum Se concentrations that are necessary for maximal GPx activity are around 1.0-1.2 $\mu \mathrm{mol} / \mathrm{l}$ (80$95 \mu \mathrm{g} / \mathrm{l}$; Thomson, 2004b), it is clear that, as for adults, the Se status of the majority of New Zealand children is unlikely to be adequate for the optimal activity of at least one of the selenoproteins. Because of the hierarchy of importance of selenoproteins, with GPx being one of the first to decline in Se deficiency and the last to increase on repletion, it is possible, but not certain, that optimal levels of other selenoproteins such as the deiodinases will have been met for many of the children. In adults in Otago, Se status may be only marginally sufficient for optimal deiodinase activity (Thomson, 2004b,c; Thomson et al. 2005), and it is therefore likely that this is also the case for children in this country. On the other hand, higher intakes may be necessary for optimal levels of another selenoprotein, selenoprotein P (Xia et al. 2005). The situation is of particular concern in the South Island, where the Se status of children is the lowest in the country.

As GPx is an important antioxidant, which appears to be involved in immune function and protection against a number of disease processes such as cancer and asthma (Rayman, 2000; Combs, 2001), children in New Zealand may be at risk from the possible consequences of inadequate Se status. Those living in the South Island of New Zealand and Mäori children are clearly at greater risk from any of these possible consequences. It would appear desirable to target public health measures to improve Se intake in children as well as adults in the South Island and to improve the Se status of Mäori children. This might be achieved by recommending the choice of bread made with whole grains and to increase the intake of other high-Se foods such as canned fish, nuts and seeds, poultry and eggs. The present study clearly shows that Se status in children in New Zealand has increased from that reported in the 1970s (McKenzie et al. 1978), as it has done in adults (Thomson \& Robinson, 1996). In many regions, however, it is still likely to be insufficient for the optimal activity of GPx and possibly other functionally important selenoproteins. If the association between Se status and cancer and between Se status and asthma is confirmed, fortification or supplementation measures may need to be considered.

\section{Acknowledgements}

The New Zealand Ministry of Health funded CNSO2 and the Se analyses. Thanks to A. Gray for additional statistical analyses.

\section{References}

Barany E, Bergdahl I, Bratteby L-E, Lundh T, Samuelson G, Schutz A, Skerfving S \& Oskarsson A (2002) Trace elements in blood and serum of Swedish adolescents: relation to gender, age, residential area, and socioeconomic status. Environ Res 89, 72-84.

Becker D, Romic Z, Krsnjavi H \& Zima Z (1992) A contribution to the world selenium map. Biol Trace Elem Res 33, 43-49.

Behne D, Hilmert H, Scheid S, Gessner H, Kyriakopoulos A \& Elger W (1989) Studies on new selenoproteins and specific selenium target tissues. In Selenium in Biology and Medicine, pp. 14-20 [A Wendel, editor]. Berlin: Springer-Verlag.

Bratter P, Negretti de Bratter VE, Jaffe WG \& Mendez Castellano H (1991) Selenium status of children living in seleniferous areas of Venezuela. J Trace Elem Electrolytes Health Dis 5, 269-270.

Brtková A, Magálová T, Babinská K \& Béderová A (1994) Serum selenium levels in Slovak population. Biol Trace Elem Res 46, $163-171$.

Chanoine J-P (2003) Selenium and thyroid function in infants, children and adolescents. Biofactors 19, 137-143.

Chen X, Yang G, Chen J, Chen X, Wen Z \& Ge K (1980) Studies on the relation of selenium and Keshan disease. Biol Trace Elem Res 2, $91-107$.

Combs GF Jr (2001) Selenium in global food systems. Br J Nutr 85, 517-547.

Cser M, Kovacs I, Bocskai E, Sziklai-Laszio I \& Adanyi N (2002) Selenium $(\mathrm{Se})$ and blood lead $(\mathrm{Pb})$ in allergic rhinitis and asthma in Hungarian children and adults. Allergy 57, 345.

Cser MA, Sziklai-Laszio I, Menzel H \& Lombeck I (1996) Selenium and glutathione peroxidase activity in Hungarian children. $J$ Trace Elem Med Biol 10, 167-173.

Darlow BA, Inder TE, Graham PJ, Sluis KB, Malpas TJ, Taylor BJ \& Winterbourn CC (1995) The relationship of selenium status to respiratory outcome in the very low birth weight infant. Pediatrics $\mathbf{9 6}$, 314-319.

Duffield AJ \& Thomson CD (1999) A comparison of methods of assessment of dietary selenium intakes in Otago, New Zealand. Br J Nutr 82, 131-138.

Duffield AJ, Thomson CD, Hill KE \& Williams S (1999) An estimation of selenium requirements for New Zealanders. Am J Clin Nutr 70, 896-903.

Erdogan M, Erdogan G, Sav H, Gullu S \& Kamel N (2001) Endemic goiter, thiocyanate overload, and selenium status in school-age children. Biol Trace Elem Res 79, 121-130.

Flatt A, Pearce N, Thomson CD, Sears M, Robinson MF \& Beasley R (1990) Reduced selenium status in asthma subjects in New Zealand. Thorax 45, 95-99.

Fraga J, Cocho de Juan J, Pico C \& Cervilla J (1994) Serum selenium levels in Spain related to different age groups. Proceedings of STDA's Fifth International Symposium 8-10 May 1994, Brussels, pp. $157-158$.

Glauser T, Titanic-Schefft M \& Pippenger C (1999) Racial differences in free radical scavenging enzyme activity in children. $J$ Child Neurol 14, 382-387.

Gregory J \& Lowe S (2000) National Diet and Nutrition Survey: Young People Aged 4 to 18 Years, vol. 1, Report of the Diet and Nutrition Survey. London: Stationery Office.

Hincal F, Basaran N, Yetgin S \& Gokmen O (1994) Selenium status in Turkey. II. Serum selenium concentration in healthy residents of different ages in Ankara. J Trace Elem Electrolytes Health Dis 8 , $9-12$.

Jacobson BH \& Lockitch G (1988) Direct determination of selenium in serum by graphite-furnace atomic absorption spectrometry with deuterium background detection and a reduced palladium modifier: agespecific reference ranges. Clin Chem 34, 709-714.

Jochum F, Terwolbeck K, Meinhold H, Behne D, Menzel H \& Lombeck I (1999) Is there any health risk of low dietary selenium supply in PKU-children? Nutrition Res 19, 349-360.

Levander OA (1982) Clinical consequences of low selenium intake and its relationship to vitamin E. Ann N Y Acad Sci 393, 70-80. 
Lombeck I (1977) The selenium state of healthy children. I. Serum selenium concentration at different ages: activity of glutathione peroxidase of erythrocytes at different ages; selenium content of food of infants. Eur J Pediatr 125, 81-88.

Manufactured Food Database (2002) Fortified Foods Available in New Zealand. Auckland: Manufactured Food Database.

Marano G, Spagnolo A, Morisi G \& Menotti A (1991) Changes of serum selenium and serum cholesterol in children during sexual maturation. J Trace Elem Electrolytes Health Dis 5, 59-61.

McKenzie RL, Rea HM, Thomson CD \& Robinson MF (1978) Selenium concentration and glutathione peroxidase activity in blood of New Zealand infants and children. Am J Clin Nutr 31, $1413-1418$

McLachlan SK, Thomson CD, Ferguson EL \& McKenzie JE (2004) Dietary and biochemical selenium status of urban 6-24 month old South Island New Zealand children and their post-partum mothers. J Nutr 134, 3290-3295.

Micetic-Turk D, Turk Z \& Radoll L (1996) Serum selenium values in healthy children aged 1-18 years in NE Slovenia. Eur J Clin Nutr 50, 192-194.

Mikac-Devic M, Ferenec D \& Tiefenbach A (1990) Selenium levels in untreated children with acute lymphoblastic leukemia. I. J Trace Elem Electrolytes Health Dis 4, 7-10.

Muntau AC, Streiter M, Kappler M, Roschinger W, Schmid I, Rehnert A, Schramel P \& Roscher AA (2002) Age-related reference values for serum selenium concentrations in infants and children. Clin Chem 48, 555-560.

Mussalo-Rauhamaa H, Vuori E, Lehto J, Akerblom H \& Rasanen L (1993) Increase in serum selenium levels in Finnish children and young adults during 1980-1986: a correlation between the serum levels and the estimated intake. Eur J Clin Nutr 47, 711-717.

New Zealand Institute of Crop \& Food Research Ltd (2002) FOODfiles: Datafiles of the New Zealand Food Composition Database, OCNZ00. Palmerston North: New Zealand Institute for Crop \& Food Research.

Parnell W, Scragg R, Wilson N, Schaaf D \& Fitzgerald E (2003) NZ Food, NZ Children, Key Results of the 2002 National Children's Nutrition Survey. Wellington: Ministry of Health.

Rayman MP (2000) The importance of selenium to human health. Lancet 356, 233-241.

Rossipal E \& Tiran B (1995) Selenium and glutathione peroxidase levels in healthy infants and children in Austria and the influence of nutrition regimens on these levels. Nutrition 11, 573-575.

Rubin R, Navon L \& Cassano P (2004) Relationship of serum antioxidants to asthma prevalence in youth. Am J Respir Crit Care Med 169, 393-398.

Salmond C \& Crampton R (2002) NZDep2001 Index of Deprivation. Wellington: Department of Public Health Wellington School of Medicine and Health Sciences, University of Otago.

Shaw R, Woodman K, Crane J, Moyes C, Kennedy J \& Pearce N (1994) Risk factors for asthma symptoms in Kawerau children [see comments]. Comment in: NZ Med J 1995; 108:178-179. N Z Med J 107, 387-391.
Stone J, Hinks LJ, Beasley R, Holgate ST \& Clayton BA (1989) Reduced selenium status in patients with asthma. Clin Sci 77, 495-500.

Thomas A, Miller W, Shenkin A, Fell G \& Taylor F (1994) Selenium and glutathione peroxidase status in paediatric health and gastrointestinal diseases. J Pediatr Gastroenterol Nutr 19, 213-219.

Thomson C, McLachlan S, Grant A, Paterson E \& Lillico A (2005) The effect of selenium on thyroid status in a population with marginal selenium and iodine status. Br J Nutr 962-968.

Thomson CD (2004a) Selenium and iodine intakes and status in New Zealand and Australia. Br J Nutr 91, 661-672.

Thomson CD (2004b) Assessment of requirements for selenium and adequacy of selenium status: a review. Eur J Clin Nutr 58, $391-402$

Thomson CD (2004c) Interaction between selenium and iodine in thyroid status. Metal Ions Biol Med 8, 552-554.

Thomson CD \& Robinson MF (1996) The changing selenium status of New Zealand residents. Eur J Clin Nutr 50, 107-114.

Thomson CD, Robinson MF, Butler JA \& Whanger PD (1993) Long-term supplementation with selenate and selenomethionine: selenium and glutathione peroxidase (EC 1.11.1.19) in blood components of New Zealand women. Br J Nutr 69, 577-588.

van Biervliet S, van Biervliet J-P, Bernard D, Matthys M, Vercaemst R \& Blaton V (2001) Serum $\alpha$-tocopherol and selenium in Belgian infants and children. Biol Trace Elem Res 79, 115-120.

van Caillie-Bertrand M, Degenhart H \& Fernandes J (1986) Influence of age on the selenium status in Belgium and The Netherlands. Pediatr Res 20, 574-576.

van Cauwenbergh R, Robberecht H \& Deelstra H (1995) Serum selenium levels in Greek B-thalassemia patients. J Trace Elem Electrolytes Health Dis 12, 20-25.

Vannoort RW \& Thomson BM (2005) 2003/04 New Zealand Total Diet Survey. Wellington: New Zealand Food Safety Authority.

Wang W-C, Näntö V, Mäkelä A \& Mäkelä P (1995) Effect of nationwide selenium supplementation status in children with juvenile rheumatoid arthritis. A ten year follow up study. Analyst 120, 955-958.

Wasowicz W, Gromadzinska J, Rydzynski K \& Tomczak J (2003) Selenium status of low-selenium area residents: Polish experience. Toxicol Lett 137, 95-101.

Watkinson JH (1981) Changes in blood selenium in New Zealand adults with time and importation of Australian wheat. Am J Clin Nutr 34, 936-942.

Xia Y, Hill KE, Byrne DW, Xu J \& Burk RF (2005) Effectiveness of selenium supplements in a low-selenium area of China. Am J Clin Nutr 81, 829-831.

Zimmerman M \& Kohrle J (2002) The impact of iron and selenium deficiencies on iodine and thyroid metabolism: biochemistry and relevance to public health. Thyroid 12, 867-878.

Zwolinska D, Grzeszczak W, Kilis-Pstrusinska K, Szprynger K \& Szczepanska M (2004) Lipid peroxidation and antioxidant enzymes in children with chronic renal failure. Pediatr Nephrol 19, $888-892$. 